\title{
Verification and evaluation of monochloropropanediol (MCPD) esters and glycidyl esters in palm oil products of different regions in Malaysia
}

\begin{abstract}
This study was conducted to investigate on the effect of different sampling regions of palm refined oils and fats on the 2- and 3-monochloropropanediol fatty acid esters (MCPDE) and glycidol fatty acid esters (GE) levels. The American Oil Chemists' Society (AOCS) Official Method Cd 29a-13 on the determination of MCPDE and GE in edible oils and fats by acid transesterification was successfully verified and optimised, with slight modification using 7890A Agilent GC system equipped with 5975C quadrupole detector. The determined limits of detection (LOD) for MCPDE were $0.02 \mathrm{mg} \mathrm{kg}^{-1}$ and $0.05 \mathrm{mg} \mathrm{kg}^{-1}$ for GE. The method performance has showed good recovery between $80 \%$ and $120 \%$ for all pertinent compounds with seven replicates assayed in three separate days. Round robin test with two European laboratories, i.e. Eurofins and SGS, has shown compliance results with those of the present study. Among the sampling regions, only one refinery located in the central region of Malaysia showed a significant increment of the MCPDE and GE levels after refining process. The GE level averaging at $2.5 \mathrm{mg} \mathrm{kg}^{-1}$ was slightly higher than that of 3-MCPDE averaging at $1.3 \mathrm{mg} \mathrm{kg}^{-1}$. Both esters were preferentially partitioned into the liquid phase rather than the solid phase after fractionation. However, the overall results exhibited no direct correlation between the esters content and the different sampling locations of the palm oil products in Malaysia. Analysis of total chlorine content also displayed significant variations between sampling locations which clearly show its effect on the chlorine content in the CPO samples.
\end{abstract}

Keyword: Monochloropropanediol (MCPD) esters; Glycidol fatty acid esters; Palm oil products; Refining oils 